\title{
CONJUGATED AMINO ACIDS IN PLASMA OF PATIENTS WITH UREMIA *
}

\author{
By GEORGE W. FRIMPTER, $\dagger$ DAVID D. THOMPSON AND E. HUGH LUCKEY
}

(From the Department of Medicine, Cornell University Medical College and The New York Hospital, New York, N. Y.)

(Submitted for publication February 2, 1961 ; accepted March 13, 1961)

In patients with renal insufficiency, the elevated plasma nonprotein nitrogen cannot be accounted for solely by the rise in the urea nitrogen (2). It is known that other nitrogenous materials such as creatinine and uric acid contribute to this elevation. Since free amino acids also contribute to the nonprotein, nonurea nitrogen of plasma, several investigators have determined the amino acid composition of plasma from both normal subjects and patients with uremia. They have shown that in uremia, concentrations of the individual plasma are normal or that such alterations in concentrations as exist are slight and probably insignificant (3-7). In addition, the total $\alpha$-amino nitrogen in plasma of patients with uremia remains approximately normal (3-10). However, studies in which deproteinized plasma was hydrolyzed revealed that some amino acids are variably increased in concentration (3-6). These findings suggested the presence of one or more amino acid conjugates in the plasma of patients with uremia.

The investigations described in this paper were undertaken to characterize further the amino acid conjugates in the plasma of patients with uremia. The general plan of the study consisted of measurement of $\alpha$-amino nitrogen in deproteinized plasma of normal subjects, and of patients with uremia before and after hydrolysis. By means of dialysis through cellophane, rough indications were obtained of the molecular size of conjugates containing nitrogen. By chromatographic separation and serial fraction collections, the sources of conjugate nitrogen were concentrated. At-

* Presented in part at the combined Annual Meetings of the American Society for Clinical Investigation and the American Federation for Clinical Research, Atlantic City, N. J., May, 1960 (1). This investigation was supported by Grant $\mathrm{H}-4148$ from the National Institutes of Health, Bethesda, Md., and a grant from the Kidney Disease Foundation of New York.

† Senior Research Fellow, New York Heart Association. tempts were then made to identify the compounds accounting for the increase in $\alpha$-amino nitrogen of plasma after hydrolysis.

\section{METHODS}

Patients. Patients used in this study had been hospitalized with symptomatic chronic renal insufficiency due to a variety of renal diseases including chronic glomerulonephritis, chronic pyelonephritis, nephrosclerosis, and congenital polycystic kidney disease. None had liver disease, diabetes mellitus, or other metabolic diseases. None had recent surgery, wounds, or infarction. None was receiving a blood transfusion at the time a specimen was obtained or within 24 hours prior to collection. Blood specimens were taken from an antecubital vein without stasis, through an 18-gage needle into a siliconized glass syringe, and transferred immediately into a siliconized Erlenmeyer flask containing $0.1 \mathrm{mg}$ of dried sodium heparin per $10 \mathrm{ml}$ of blood. The cells were separated promptly by centrifugation and the plasma was processed immediately.

Alpha-amino nitrogen before and after hydrolysis. Plasma proteins were removed by precipitation with 1 per cent picric acid (10). The picric acid was subsequently removed by passage of a measured portion of the filtrate through a Dowex- 2 resin column as described by Stein and Moore (11). Ultrafiltration through Visking cellophane was performed at $4^{\circ} \mathrm{C}$ under 400 pounds per square inch of $\mathrm{N}_{2}$ pressure (12). An aliquot of each filtrate was then hydrolyzed by sealing it with an equal volume of $12 \mathrm{~N}$ hydrochloric acid in a Pyrex test tube under nitrogen, and heating at $110^{\circ}$ for 22 hours. The acid was subsequently removed on a rotary evaporator. The ninhydrin reaction was performed in triplicate at pH 2.5 by the gasometric ninhydrin method of Hamilton and Van Slyke (10).

Because some $\mathrm{CO}_{2}$ evolves from urea in the ninhydrin reaction, it was found desirable to remove the urea. Triplicate aliquots of each specimen, before and after hydrolysis, were placed in the ninhydrin reaction vessels, buffered to $\mathrm{pH} 6.1$, and incubated 12 hours at $40^{\circ} \mathrm{C}$ with urease $(10)$. The urease had previously been purified by dialysis to remove canavanine and other ninhydrinreacting substances, thus reducing the "blank" determination (13). After 12 hours of incubation the reaction mixture was found to be free of urea, as determined by the method of Van Slyke and Cullen (14). Under the conditions described, less than 12 hours' incubation with 
urease was inadequate. The 12 hours of incubation did not alter the $\alpha$-amino nitrogen determination of sample plasmas. Recovery of $\alpha$-amino nitrogen added as glycine and glutamic acid to uremic plasma was $100 \pm 2$ per cent. Plasma urea nitrogen was performed in duplicate (14) ; uremic plasma specimens were diluted with water (usually $1: 10$ ) so that all titrations were performed in the same range.

Dialysis of amino acid conjugates. After removal of picrate, plasma filtrates were concentrated $4 \times$ on a rotary evaporator and adjusted to $\mathrm{pH} 3.4$. Using the Craig, King and Stracher dialysis cell (15), $2 \mathrm{ml}$ of the specimen was placed in an acetylated $18 / 32$ Visking cellophane sac which was then transferred through a series of test tubes containing $5 \mathrm{ml}$ of $0.01 \mathrm{M}$ acetic acid, $\mathrm{pH}$ 3.4 (15). Analyses performed on the dialysate, on an aliquot of the initial specimen, and on the material remaining in the sac at the end of the experiment included: colorimetric ninhydrin after alkaline hydrolysis in triplicate (16), urea (14), glucose (17).

Chromatographic separation of amino acid conjugates on ion-exchange resins. A picric acid plasma filtrate was added to the top of a $1.8 \times 165 \mathrm{~cm}$ column of Amberlite 1R 120 resin (18) equilibrated with $0.2 \mathrm{~N}, \mathrm{pH}$ 2.20 sodium citrate (19), or $0.2 \mathrm{~N}$, pH 3.25 sodium citrate buffer $(20)$. These were pumped through at a rate of $50 \mathrm{ml}$ per hour, and approximately $3003.0-\mathrm{ml}$ fractions were collected. Unhydrolyzed aliquots of these fractions were analyzed for color developed with ninhydrin (21). Additional aliquots of these same fractions

TABLE I

Free and conjugated $\alpha$-amino nitrogen

\begin{tabular}{|c|c|c|c|c|}
\hline & $\begin{array}{l}\text { Plasma } \\
\text { urea N }\end{array}$ & $\alpha$-Amino $\mathrm{N}$ & $\begin{array}{c}\text { Post- } \\
\text { hydrolysis } \\
\alpha \text {-amino N }\end{array}$ & 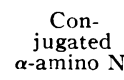 \\
\hline & $m g \%$ & $m g \%$ & $m g \%$ & $m g \%$ \\
\hline \multicolumn{5}{|c|}{ I. Normal subjects } \\
\hline $\begin{array}{l}1 \\
2 \\
3 \\
4 \\
5\end{array}$ & $\begin{array}{l}11.5 \\
12.0 \\
11.8 \\
13.3 \\
11.4\end{array}$ & $\begin{array}{l}4.9 \\
4.4 \\
3.9 \\
3.4 \\
4.2\end{array}$ & $\begin{array}{l}5.7 \\
5.1 \\
4.9 \\
3.6 \\
4.3\end{array}$ & $\begin{array}{l}0.8 \\
0.7 \\
1.0 \\
0.2 \\
0.1\end{array}$ \\
\hline Mean & 12.0 & 4.1 & 4.7 & 0.6 \\
\hline \multicolumn{5}{|c|}{ II. Uremic patients } \\
\hline $\begin{array}{c}1 \\
2, a^{*} \\
\text { b† } \\
3 \\
4 \\
5 \\
6 \\
7 \\
8 \\
9 \\
10\end{array}$ & $\begin{array}{r}318 \\
177 \\
235 \\
175 \\
187 \\
122 \\
200 \\
220 \\
183 \\
95 \\
240\end{array}$ & $\begin{array}{l}4.4 \\
3.4 \\
4.1 \\
5.4 \\
5.7 \\
5.3 \\
4.4 \\
5.3 \\
3.6 \\
4.3 \\
5.5\end{array}$ & $\begin{array}{r}6.2 \\
6.1 \\
11.2 \\
11.8 \\
7.2 \\
7.8 \\
7.2 \\
7.0 \\
5.9 \\
6.2 \\
8.1\end{array}$ & $\begin{array}{l}1.8 \\
2.7 \\
7.1 \\
6.4 \\
1.5 \\
2.5 \\
2.8 \\
1.7 \\
2.3 \\
1.9 \\
2.6\end{array}$ \\
\hline Mean & 195 & 4.7 & 7.7 & 3.0 \\
\hline
\end{tabular}

* On admission.

$\dagger$ Two weeks later.
TABLE II

Picric acid versus ultrafiltration

\begin{tabular}{|c|c|c|c|c|}
\hline & $\begin{array}{l}\text { Plasma } \\
\text { urea N }\end{array}$ & $\alpha-{ }_{N}^{A \operatorname{mino}}$ & $\begin{array}{c}\text { Post- } \\
\text { hydrolysis } \\
\alpha \text {-amino N }\end{array}$ & $\underset{\alpha \text {-amino } N}{\text { Con- }}$ \\
\hline Normal & $m g \%$ & $m g \%$ & $m g \%$ & $m g \%$ \\
\hline $\begin{array}{l}\text { Picric acid } \\
\text { Ultrafiltration }\end{array}$ & 11.4 & $\begin{array}{l}4.2 \\
4.5\end{array}$ & $\begin{array}{l}4.3 \\
4.6\end{array}$ & $\begin{array}{l}0.1 \\
0.1\end{array}$ \\
\hline Uremic & & & & \\
\hline $\begin{array}{l}\text { Picric acid } \\
\text { Ultrafiltration }\end{array}$ & 240 & $\begin{array}{l}5.5 \\
5.6\end{array}$ & $\begin{array}{l}8.1 \\
7.5\end{array}$ & $\begin{array}{l}2.6 \\
1.9\end{array}$ \\
\hline
\end{tabular}

were subjected to an arbitrary acid hydrolysis ( 1 hour in boiling water bath with equal volume of $6 \mathrm{~N} \mathrm{HCl}$ ), were neutralized with $\mathrm{NaOH}$ and the color developed with ninhydrin was determined. Identity and location of amino acids in the eluate were established by use of known standards and paper chromatography. Urea was identified by the urease reaction (14). Fractions containing substances localized by the ninhydrin reactions before and after hydrolysis were pooled, and the volume was reduced on a rotary evaporator. Analysis for peptide was performed by the biuret (22) and the LowryFolin reactions (23). Chromatography on a basic resin, Dowex $1-\times 4$ (acetate), was performed according to the method of Stein, Paladini, Hirs and Moore (24). Glucose was determined by the Somogyi reagent (17). Phosphate was determined by the method of Lowry and Lopez (25) before and after acid hydrolysis of the specimens.

\section{RESULTS}

Alpha-amino nitrogen before and after hydrolysis. In ten patients with uremia, free $\alpha$-amino nitrogen in plasma ranged from 3.4 to $5.7 \mathrm{mg}$ per $100 \mathrm{ml}$, with a mean of 4.7 . In five healthy control subjects, the $\alpha$-amino nitrogen ranged from 3.4 to $4.9 \mathrm{mg}$ per $100 \mathrm{ml}$, with a mean of 4.1 . These values for free plasma $\alpha$-amino nitrogen are in accord with normal values established by ot'ner workers $(9,10,26,27)$. After hydrolysis there was a mean increase of $0.6 \mathrm{mg}$ per $100 \mathrm{ml}$ (range, 0.1 to 1.0 ) in the normal plasmas. In deproteinized plasmas from patients with uremia, this increase ranged from 1.5 to $7.1 \mathrm{mg}$ per $100 \mathrm{ml}$, with a mean increase of 3.0. The data are presented in Table I. Similar results were obtained when plasma was deproteinized by ultrafiltration (Table II). Only a small number of ultrafiltrations was performed, since the method involves definite possibilities for error in procedure, as well as in theory. While the limited data precluded statisti- 


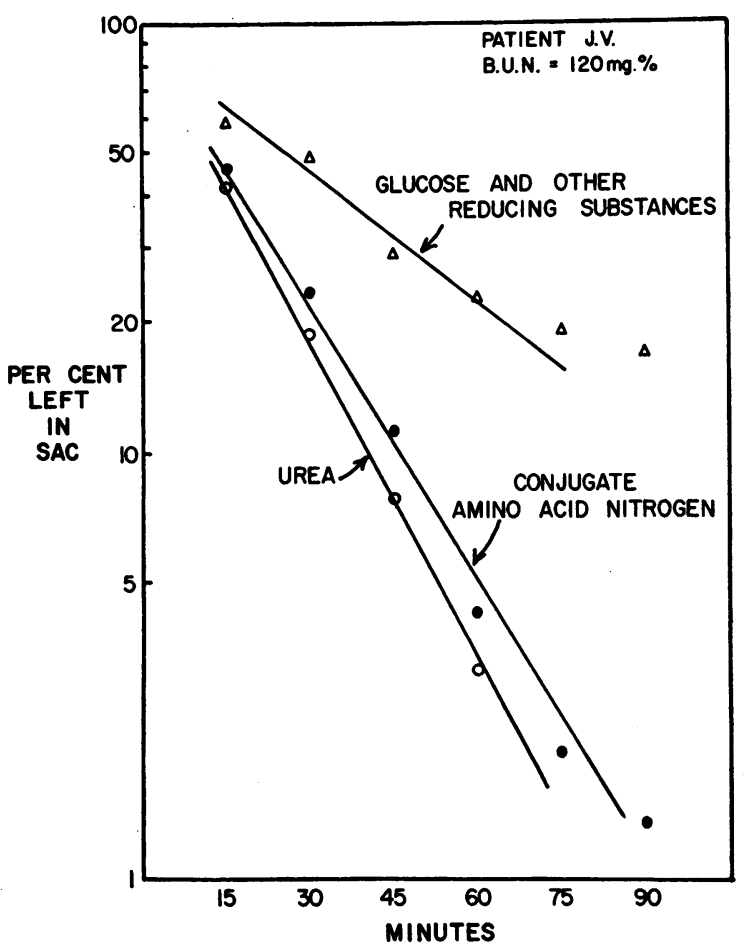

Fig. 1. Conjugated amino $\mathrm{N}$ dialyzed through CELLOPHANE AT A RATE FASTER THAN UREA BUT SLOWER THAN GLUCOSE.

cal comparison, it was our impression that picric acid deproteinization, although less convenient than ultrafiltration, gives more consistent results. This agrees with the findings of other workers (11).

Dialysis of amino acid conjugates. The compounds which gave rise to the increased $\alpha$-amino nitrogen upon hydrolysis dialyzed rapidly through cellophane. Efforts to increase the selectivity of the experiment by slowing the rate of dialysis were only partially successful, although acetylation of the membrane and dialyzing into $0.01 \mathrm{M}$ acetic acid did slow the rate, as noted by Craig and co-workers (15). After one experiment, manometric $\mathrm{CO}_{2}$-ninhydrin determinations on the dialysate were made, but dialysis of the unknown proceeded so rapidly that the concentration of $\alpha$-amino nitrogen (after hydrolysis) in the dialysate fell off quickly. That is, only the earliest tubes of dialysate contained any reliably detectable $\alpha$-amino nitrogen. The colorimetric ninhydrin method was applied and proved to be more sensitive than the manometric method. In these experiments alkaline hydrolysis was selected because any ammonia formed would be driven off. In specimens from normal subjects, there was essentially no conjugated amino nitrogen, as shown by a lack of change in ninhydrin color after hydrolysis. In specimens from patients with uremia, conjugate $\mathrm{N}$ dialyzed at a rate slower than that of urea, but faster than that of glucose (Figure 1). When the simple tripeptide glycylglycylglycine (mol wt 189) was added to deproteinized normal plasma, it dialyzed at the same rate as glucose (mol wt 185). Similar results were obtained on specimens deproteinized by ultrafiltration.

Chromatographic separation of amino acid conjugates on ion-exchange resins. Figure 2 illustrates the amino acid pattern obtained by ion-exchange chromatography on Amberlite 1R 120 of picric acid-deproteinized normal plasma. It can be seen that no additional peaks resulted upon hydrolysis; i.e., no conjugated amino $\mathrm{N}$ was detected in the range examined. At the end of the scheme shown in Figure 2, the $\mathrm{pH}$ was progressively raised, resulting in separation and elution of the acidic, neutral, and basic amino acids in series (20) (vide infra).

Figure 3 illustrates the typical result obtained in an identical experiment with a similarly prepared plasma from a patient with uremia. After hydrolysis of aliquots of the fractions, three distinct peaks, labeled $\mathrm{A}, \mathrm{B}$, and $\mathrm{C}$ were found where there was little or no color prior to hydrolysis. Chromatography of the contents of peak $\mathrm{C}$ on Dowex-1 resulted in a single peak detectable only by performing the ninhydrin color after hydrolysis. Hydrolysis of pooled fractions was performed in a sealed glass tube with $6 \mathrm{~N} \mathrm{HCl}$, after which the $\mathrm{HCl}$ was evaporated. When the desalted (28) specimen was examined by two-dimensional paper chromatography, a single spot of glutamic acid was identified. An aliquot of the hydrolysate, which was subjected to quantitative analysis by an ion-exchange chromatography system employing an automatic recorder (27), revealed only glutamic acid and ammonia. This substance, therefore, had the properties of phenylacetylglutamine (PAG) as determined by Stein, Paladini, Hirs and Moore (24).

Synthetic PAG was obtained from Dr. William Stein and Dr. Stanford Moore of The Rockefeller Institute. Additional synthetic PAG was pre- 


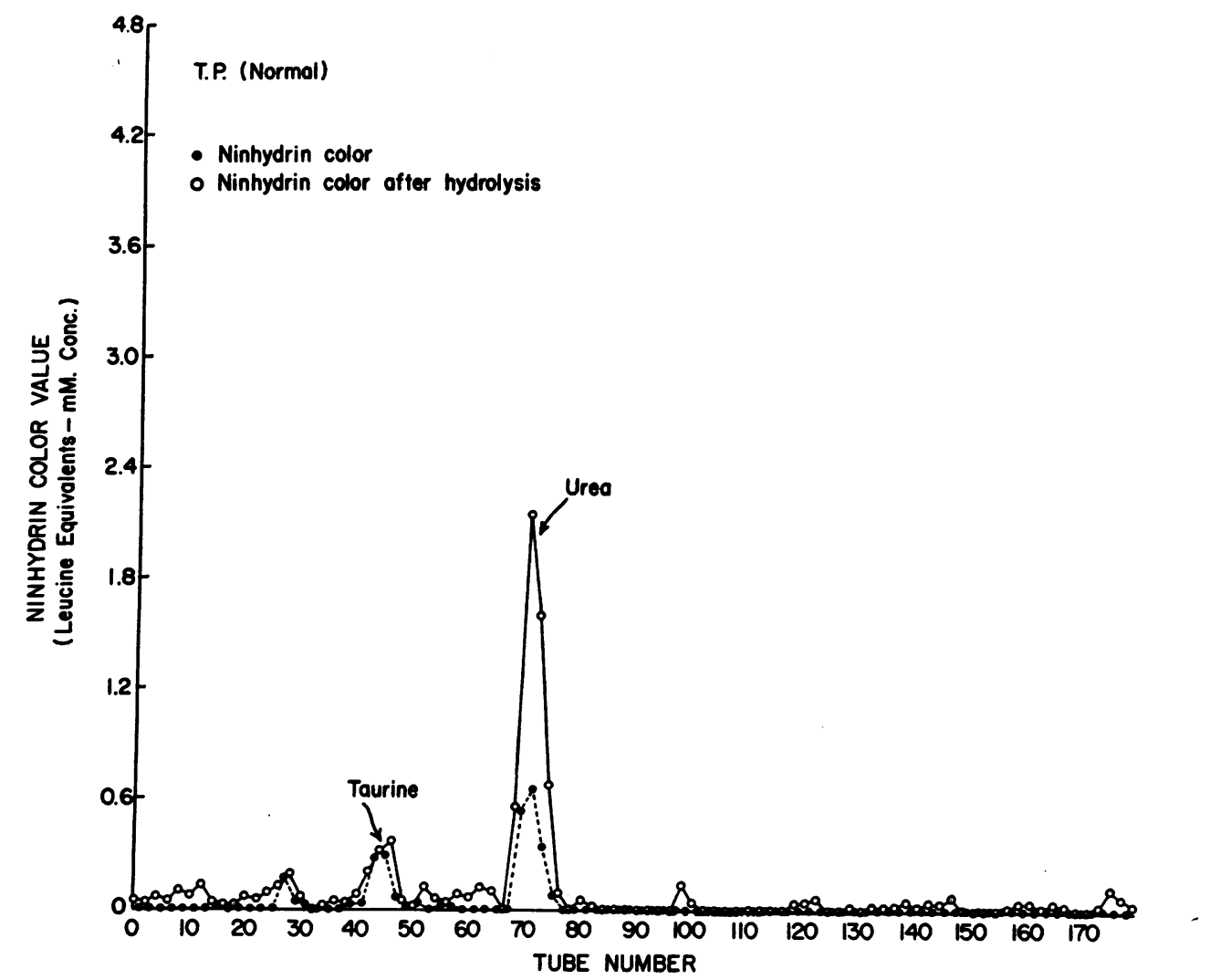

Fig. 2. ION-EXChANGe Chromatogram ON DEPRoteinized PlaSma From NORMAL SUbJeCt.

pared in our laboratory according to the method of Thierfelder and Sherwin (29). Chromatography of both samples of synthetic PAG specimens on the Amberlite 1R 120 preparative column followed by the arbitrary 1 hour hydrolysis of aliquots of effluent fractions yielded over-all recoveries of $0.93,1.14,1.19,0.93$, and 1.18 , with a mean of 1.1. The yields greater than unity may be due to ammonia liberated from glutamine together with the $\alpha$-amino $\mathrm{N}$ of glutamic acid. The mean factor (1.1), was used to estimate PAG concentration in the plasma of 10 patients with uremia, as shown in Table III.

Peaks A and B contained carbohydrate, identified as the plasma glucose. This glucose caused considerable humin formation on hydrolysis of concentrated fractions, and otherwise complicated the further handling of these unknown substances. It seemed probable that the contents of the peaks were acidic and would be retained on a basic resin, as was PAG. However, attempts at further separation by chromatography using vari- ous systems employing basic resins were not successful, the unknown usually eluting in a broad smear without peaks. The same negative results were obtained with paper chromatography and paper electrophoresis. When the contents of peak B were subjected to acid hydrolysis in a sealed tube and were chromatographed on the analytical ion-exchange resin system (30), several acidic

TABLE III

Plasma urea $N$ and phenylacetylglutamine levels in uremic patients

\begin{tabular}{llr}
\hline & Urea N & PAG \\
\hline & & $m g \%$ \\
A.S. & 200 & 5.9 \\
L.O. & 194 & 3.5 \\
E.R. & 240 & 5.2 \\
Y.B. & 217 & 12.2 \\
V.W. & 200 & 20.0 \\
J.W. & 248 & 8.1 \\
H.B. & 144 & 5.1 \\
R.B. & 133 & 3.2 \\
J.A. & 222 & 8.2 \\
G.T. & 295 & 5.5 \\
\hline
\end{tabular}


and neutral amino acids were identified, as shown in Figure 4. The prominent peak at 80 effluent ml displayed an optical density at $440 \mathrm{~m} \mu$ which is higher than that seen with urea which is eluted in this area. An aliquot of the hydrolysate (prior to this chromatography) gave a negative urease reaction. The contents of this peak were not identified, but a dense brownish mass, probably representing a fraction of the soluble humin, was eluted from the column at a time corresponding to this peak. No basic amino acids were present. Chromatography of the unhydrolyzed specimen yielded a small ninhydrin-positive peak emerging before the position of taurine. Peak A yielded the same amino acids after acid hydrolysis as did peak B.

Other amino acid conjugates. The large increase in ninhydrin color after hydrolysis of the tubes containing urea suggested that this peak might contain other amino acid conjugates. However, when the tubes were pooled, the volume reduced by evaporation, and the contents hydro- lyzed, no amino acids were found upon ionexchange chromatography. The concentration of taurine was not specifically determined in the plasmas studied but appeared to be variable. No additional amino acids were found underlying the taurine peak. In two experiments, the automatic recording apparatus employing a $150 \times 0.9$ $\mathrm{cm}$ resin column for acidic and neutral ninhydrinreacting components and a $50 \times 0.9 \mathrm{~cm}$ column for basic components (30) was modified to allow splitting of the effluent stream at the bottom of the column (31). One-tenth of the effluent was directed through the reaction bath and photometers of the apparatus in the normal fashion. The remainder was directed to a fraction collector, and over $6002.0-\mathrm{ml}$ fractions were collected. The experiment was continued for several hours past the position of $\beta$-aminoisobutyric acid on the 150 $\mathrm{cm}$ column and the emergence of arginine on the $50 \mathrm{~cm}$ column. In one experiment, both alkaline and acid hydrolysis were performed on aliquots of each fraction. In the second experiment, only

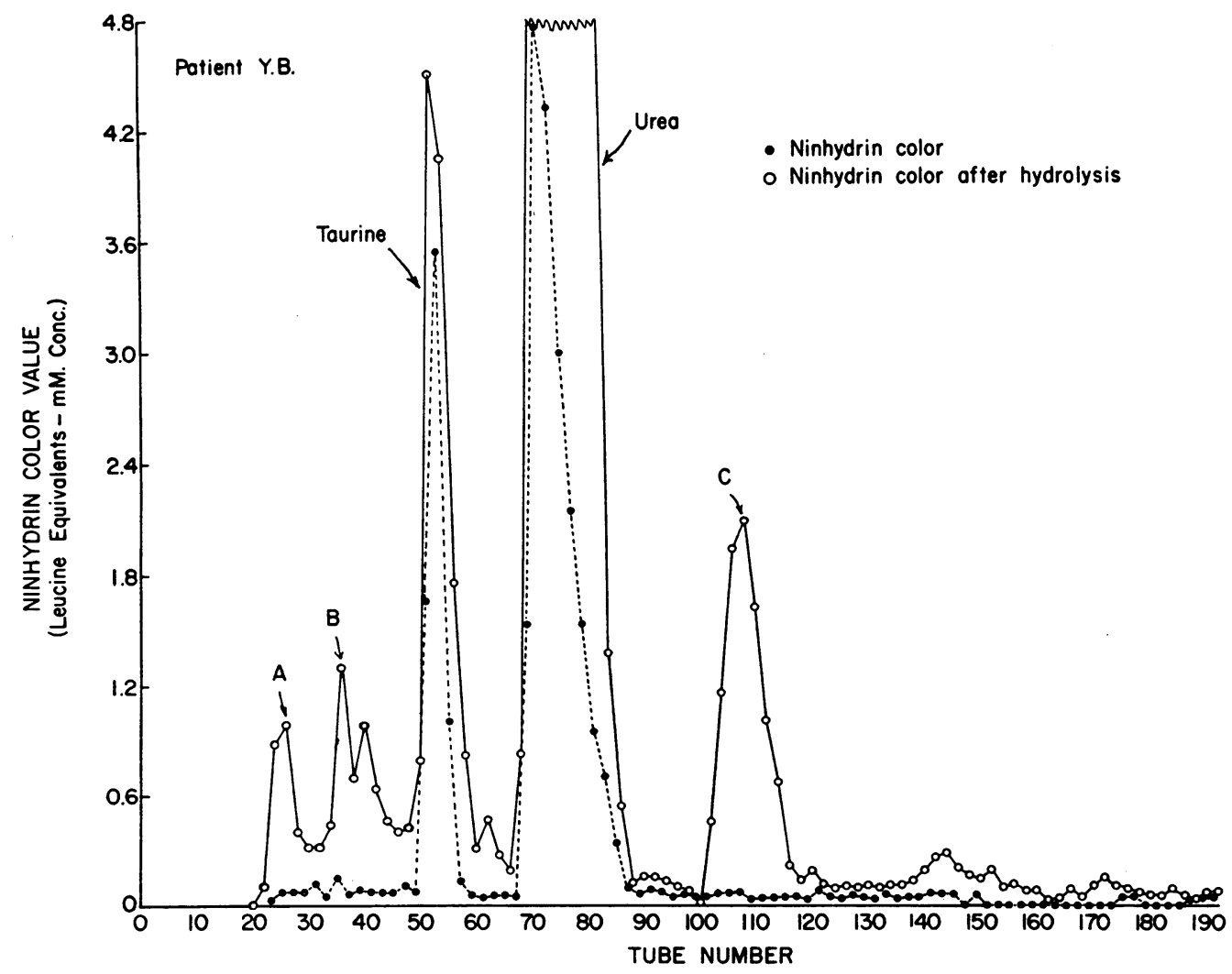

Fig. 3. Ion-exchange chromatogram on deproteinized plasma from a URemic Subject. Plasma urea N $217 \mathrm{mg}$ per $100 \mathrm{ml}$, phenylacetylglutamine $12.2 \mathrm{mg}$ per $100 \mathrm{ml}$. 


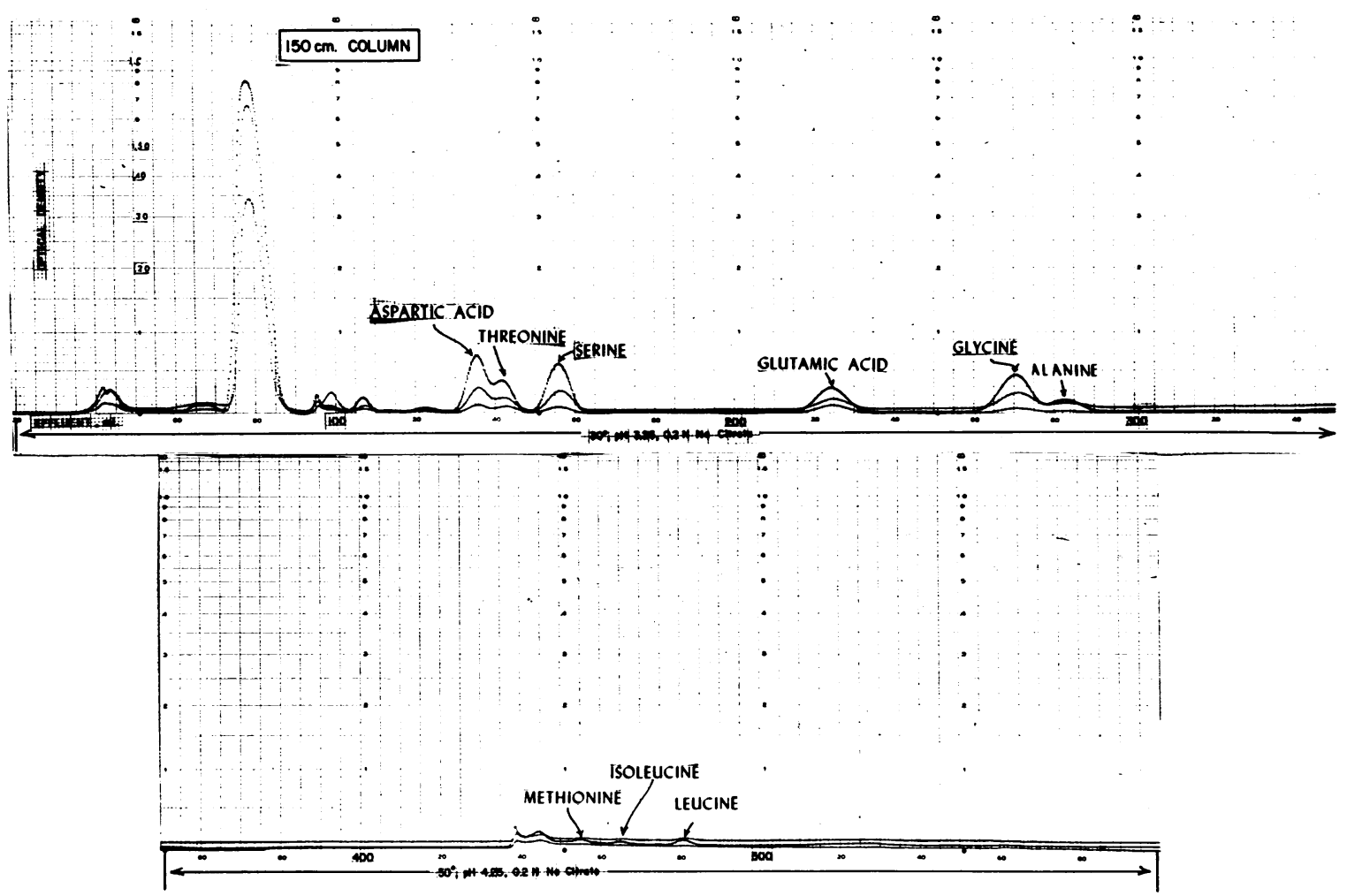

Fig. 4. Recording from automatic amino acid ion-exchange chromatogram of contents of peak B, FigURE 3, AFTER ACID HYDROLYSIS. The material in the early part of the record represents decomposition products from the plasma glucose and citrate buffer from the preparatory separation (see text).

the previously described 1 hour acid hydrolysis was used. In these experiments no prominent conjugate other than PAG and the peaks $\mathrm{A}$ and B were noted. A small post-hydrolysis peak was found between the peaks of glutamine-asparagine and proline. This peak contained only glycine after hydrolysis. The contents of tubes corresponding to the peaks of plasma amino acids were pooled, hydrolyzed, de-salted, and examined by paper chromatography. In no instance was there found any additional amino acid which would indicate a conjugate obscured on the chromatograph recording by the expected amino acid.

Because of our failure to locate hippuric acid, a conjugate known to be present in normal urine (24), radioactive hippuric acid was synthesized from $\mathrm{C}^{14}$-glycine and benzoyl chloride (32). On the $1.8 \times 165 \mathrm{~cm}$ column, $\mathrm{C}^{14}$-hippuric acid was not eluted with the $\mathrm{pH} 2.2$ buffer but was eluted with $\mathrm{pH} 3.25$ buffer in a complex peak which also contained serine, glutamine, and asparagine. On the $0.9 \mathrm{~cm}$ column of the automatic apparatus, the
$\mathrm{C}^{14}$-hippuric acid was eluted in a position corresponding to that of the unknown glycine-containing peak in plasma from patients with uremia.

\section{DISCUSSION}

The finding of increased $\alpha$-amino nitrogen after hydrolysis of cleproteinized plasma from patients with uremia confirms the findings of previous investigators (2-7). The dialysis experiments indicated that the substances giving rise to increased ninhydrin color after alkaline hydrolysis were of low molecular weight.

Our observations indicate that deproteinized plasma from patients with uremia contains amino acid conjugates which were separated into three groups on an ion-exchange resin column. One of these contained phenylacetylglutamine as the sole conjugate. Although not previously demonstrated, PAG might be expected to be found free in the plasma of patients with uremia, in view of the quantity normally excreted. Stein and co-workers 
reported a normal daily excretion of 250 to 500 $\mathrm{mg}$ (24). However, the amount of PAG apparently present in the plasmas from patients with uremia was surprisingly large. The fact that none was detected in the plasma specimens from normal subjects suggests that PAG is secreted by the renal tubules, as are similar acyl amino acids (33). Furthermore, there is evidence that excreted PAG is synthesized in part in the renal tubular cells (34).

It is interesting to compare the apparent retention of PAG with that of hippuric acid, a similar amino acid conjugate. Stein and colleagues reported a normal daily excretion of hippuric acid of 1.0 to $2.5 \mathrm{~g}$ (24). In contrast to PAG, only relatively small amounts of hippuric acid were apparently present in our plasmas from patients with uremia. This might have been partially attributable to the method employed, since PAG would liberate $\mathrm{NH}_{3}$ on acid hydrolysis and thereby increase the ninhydrin color value, whereas hippuric acid would not. Also, hippuric acid was eluted at a more complicated position in the ionexchange chromatogram. Alternative explanations for the relatively low plasma hippuric acid should be considered. First, there might be a decrease in the formation of hippurate. The origin of benzoic acid to form urinary hippuric acid is not known and may be, at least in part, dietary. These patients had poor dietary intake. Second, the production of $\mathrm{PAG}$ might be increased in some way, perhaps as the result of accelerated endogenous protein catabolism. The answer to the problem must be complicated and may include consideration of the differential effect of the uremic state upon many enzyme systems.

The presence of large amounts of PAG in the plasma of patients with uremia raised the question of whether the precursors might be increased in concentration. One of these, phenylacetic acid (PAA), has been shown to have untoward effects in man (35). However, plasma concentrations of glutamine in patients with uremia are essentially normal (3-6) and should be adequate to combine with PAA. We were unable to demonstrate the presence of PAA in plasma from patients with uremia. Whole plasma from such patients in amounts up to $250 \mathrm{ml}$ (pooled) was acidified and extracted $5 \times$ with dichloromethane.
Evaporation yielded an oily, brownish material which was more plentiful and darker than that similarly obtained from plasma from normal subjects. This material was subjected to paper chromatography according to the method of Ladd and Nossal (36). No PAA was found in the extracts, although standard organic acids chromatographed well. This does not rule out the possibility that PAA may be present in the plasma of patients with uremia; current methods for detection of PAA lack sensitivity and specificity.

The question of the effects of PAG in such large amounts in the plasma naturally arises. We have not studied the toxicity of PAG, nor have others reported on this subject. A large number of nonprotein nitrogenous substances is known to be present in increased amounts in the plasma in uremia. These include urea, creatinine, phenols, and so forth. Although each of these substances may have untoward effects under certain circumstances, it is generally accepted that the uremic syndrome is due to a multiplicity of factors rather than a single agent $(37,38)$.

Moldave and Meister noted that the enzyme of human liver and kidney which is responsible for the conjugation of glutamine with phenylacetate to form PAG also catalyzes the reaction of phenylacetate with glycine to form a slight amount of phenylacetylglycine in vitro (34). $\mathrm{C}^{14}$-phenylacetylglycine was synthesized by reacting $\mathrm{C}^{14}$-glycine with phenylacetyl chloride (29). This substance was eluted at 612 effluent $\mathrm{ml}$ from the $1.8 \times$ $165 \mathrm{~cm}$ column with the $\mathrm{pH} 2.2$ buffer. Nothing was found in this area in our studies of patients with uremia. Therefore, phenylacetylglycine was not present in the plasma of our patients with uremia.

The material in the peaks labeled A and B has not been completely identified. Although some amino acids were identified after hydrolysis, the usual tests for proteins and peptides were negative. The manner of deproteinization and the dialysis experiments also tend to militate against the presence of peptides. This confirms the observations of Christensen and co-workers, who were unable to find an increase in nondialyzable $\alpha$-amino $\mathrm{N}$ in deproteinized uremic plasma (39). Significant amounts of phosphate were not present in spite of the fact that phosphoethanolamine, 
glycerophosphoethanolamine, and phosphoserine are eluted before taurine in the method of Spackman, Stein and Moore (30). Since one organic acid, phenylacetic acid, is a constituent of one conjugate (peak $\mathrm{C}$ ) it is conceivable that other conjugates (peaks $\mathrm{A}$ and $\mathrm{B}$ ) represent conglomerates of amino acids with other organic substances.

The two types of study, 1) $\alpha$-amino $\mathrm{N}$ before and after hydrolysis, and 2) chromatographic separation of amino acid conjugates on ion-exchange resins, were not performed on the same specimens. It is apparent that even $20 \mathrm{mg}$ per $100 \mathrm{ml}$ of PAG would yield only about $1 \mathrm{mg}$ per $100 \mathrm{ml}$ of $\alpha$-amino $\mathrm{N}$. It is difficult to estimate the amount of $\alpha$-amino $\mathrm{N}$ contributed by the conjugates which were incompletely identified. However, it may be anticipated that other analytical procedures will reveal additional sources for the $\alpha$-amino $N$ liberated by acid hydrolysis.

\section{SUMMARY AND CONCLUSIONS}

1. We have confirmed the observation that the $\alpha$-amino nitrogen in deproteinized plasma from patients with uremia is approximately normal. Acid hydrolysis of deproteinized plasma of uremic patients resulted in an increase in $\alpha$-amino nitrogen of 1.5 to $7.1 \mathrm{mg}$ per $100 \mathrm{ml}$, with a mean increase of 3.0 ( 65 per cent), compared with a mean of $0.6 \mathrm{mg}$ per $100 \mathrm{ml}$ (11 per cent) in normal plasmas.

2. The substances apparently giving rise to the increased $\alpha$-amino nitrogen dialyzed through cellophane at a rate slower than that of urea, but faster than that of glucose.

3. Amino acid conjugates were separated on ion-exchange resins. Phenylacetylglutamine was found in amounts up to $20 \mathrm{mg}$ per $100 \mathrm{ml}$ in plasma of patients with chronic uremia. Thus, phenylacetylglutamine accounts for a portion of the rise in $\alpha$-amino nitrogen after hydrolysis of uremic plasmas. No correlation of the concentrations of phenylacetylglutamine with plasma urea nitrogen levels was apparent.

4. Evidence for the presence of other conjugates is offered. The amino acids present in these conjugates were identified. The structure of the organic compounds containing these amino acids has not been determined and requires further study.

\section{ACKNOWLEDGMENT}

The authors wish to thank physicians of The New York Hospital who permitted us to study their patients. The advice of Dr. Abraham Mazur and Dr. Ralph E. Peterson was invaluable in the approach to the problem. We are indebted to Dr. Kenneth Woods whom we consulted on the ion-exchange chromatographic procedures. Dr. John F. Thompson of the US Dept. of Agriculture Laboratory, Cornell University, Ithaca, N. Y., kindly advised us on de-salting and paper chromatographic techniques. Drs. William Stein and Stanford Moore of The Rockefeller Institute kindly provided a specimen of synthetic phenylacetylglutamine. Miss Naomi Schecter and Mrs. Martha Barrett MacLeod helped with the ninhydrin analyses. Miss Audrey Bass operated the automatic amino acid analyzer.

\section{REFERENCES}

1. Frimpter, G. W., and Thompson, D. D. Conjugated amino acids in deproteinized plasma of patients with renal failure (abstract). J. clin. Invest. 1960, 39, 987.

2. Merrill, J. P., Smith, S., III, Callahan, E. J., III, and Thorn, G. W. The use of an artificial kidney. II. Clinical experience. J. clin. Invest. 1950, 29, 425.

3. Levenson, S. M., Howard, J. M., and Rosen, H. Studies of plasma amino acids and amino conjugates in patients with severe battle wounds. Surg. Gynec. Obstet. 1955, 101, 35.

4. Doolan, P. D., Harper, H. A., Watten, R. H., Hutchin, M. E., and Canada, R. O. Changes in plasma amino acids and blood oxygen content during dialysis with the Kolff-Merrill artificial kidney. Trans. Amer. Soc. artif. intern. Organs 1956, 2, 113.

5. Salisbury, P. F., Dunn, M. S., and Murphy, E. A Apparent free amino acids in deproteinized plasma of normal and uremic persons. J. clin. Invest. 1957, 36, 1227.

6. Rosen, H., Meroney, W. H., and Levenson, S. M Plasma amino acids in patients with renal failure. Effect of extracorporeal haemodialysis. Clin. Sci. 1958, 17, 653.

7. Woods, K. R. Plasma amino acids before and after extracorporeal hemodialysis in renal failure. Clin. Res. 1960, 8, 235.

8. Foster, N. B. Uremia. III. The non-protein nitrogen of blood. Arch. intern. Med. 1915, 15, 356.

9. Chinard, F. P., and Van Slyke, D. D. Comparison of a modified Folin photometric procedure and the ninhydrin manometric method for the determination of amino acid nitrogen in plasma. J. biol. Chem. 1947, 169, 571.

10. Hamilton, P. B., and Van Slyke, D. D. The gasometric determination of free amino acids in blood filtrates by the ninhydrin-carbon dioxide method. J. biol. Chem. 1943, 150, 231. 
11. Stein, W. H., and Moore, S. The free amino acids of human blood plasma. J. biol. Chem. 1954, 211, 915.

12. Rosen, H., and Levenson, S. M. The nature of undetermined nitrogen in rats following burns. Army Med. Nutrition Lab. Report no. 87, 1951.

13. Archibald, R. M., and Hamilton, P. B. Removal of canavanine from preparations of jack bean urease. J. biol. Chem. 1943, 150, 155.

14. Van Slyke, D. D., and Cullen, G. E. A permanent preparation of urease, and its use in the determination of urea. J. biol. Chem. 1914, 19, 211.

15. Craig, L. C., King, T. P., and Stracher, A. Dialysis studies. II. Some experiments dealing with the problem of selectivity. J. Amer. chem. Soc. 1957, 79, 3729.

16. Hirs, C. H. W., Moore, S., and Stein, W. H. Peptides obtained by tryptic hydrolysis of performic acid-oxidized ribonuclease. J. biol. Chem. 1956, $219,623$.

17. Somogyi, M. A new reagent for the determination of sugars. J. biol. Chem. 1945, 160, 61 .

18. Hamilton, P. B., and Anderson, R. A. Ion exchange chromatography of amino acids. Semiautomatic method of operation with cationic exchange resin columns. Analyt. Chem. 1959, 31, 1504.

19. Moore, S., and Stein, W. H. Procedures for the chromatographic determination of amino acids on four per cent cross-linked sulfonated polystyrene resins. J. biol. Chem. 1954, 211, 893.

20. Moore, S., Spackman, D. H., and Stein, W. H. Chromatography of amino acids on sulfonated polystyrene resins. An improved system. Analyt. Chem. 1958, 30, 1185.

21. Moore, S., and Stein, W. H. A modified ninhydrin reagent for the photometric determination of amino acids and related compounds. J. biol. Chem. 1954, 211, 907.

22. Hiller, A., Greif, R. L., and Beckman, W. W. Determination of protein in urine by the biuret method. J. biol. Chem. 1948, 176, 1421.

23. Lowry, O. H., Rosebrough, N. J., Farr, A. L., and Randall, R. J. Protein measurement with the Folin phenol reagent. J. biol. Chem. 1951, 193, 265.

24. Stein, W. H., Paladini, A. C., Hirs, C. W. H., and Moore, S. Phenylacetylglutamine as a constituent of normal human urine. J. Amer. chem. Soc. 1954, $76,2848$.

25. Lowry, O. H., and Lopez, J. A. The determination of inorganic phosphate in the presence of labile phosphate esters. J. biol. Chem. 1946, 162, 421.
26. Cramer, F. B., Jr., and Winnick, T. Amino acid nitrogen of normal human plasma. J. biol. Chem. 1943, 150, 259.

27. Bonsnes, R. W. The plasma amino acid and amino nitrogen concentration during normal pregnancy, labor, and early purperium. J. biol. Chem. 1947, 168, 345.

28. Thompson, J. F., Morris, C. J., and Gering, R. K. Purification of plant amino acids for paper chromatography. Analyt. Chem. 1959, 31, 1028.

29. Thierfelder, H., and Sherwin, C. P. Phenylacetylglutamin und seine Bildung im menschlichen Körper nach Eingabe von Phenylessigsäure. $Z$. physiol. Chem. 1915, 94, 1.

30. Spackman, D. H., Stein, W. H., and Moore, S. Automatic recording apparatus for use in the chromatography of amino acids. Analyt. Chem. 1958, 30, 1190.

31. Woods, K. R., and Engle, R. L., Jr. Automatic analysis of amino acids. Ann. N. Y. Acad. Sci. 1960, 87, 764.

32. Mitchell, H. H., and Hamilton, T. S. The Biochemistry of the Amino Acids. New York, Chemical Catalog Co., 1929, p. 71.

33. Schachter, D., Manis, J. G., and Taggart, J. V. Renal synthesis, degradation and active transport of aliphatic acyl amino acids: Relationship to $p$-aminohippurate transport. Amer. J. Physiol. 1955, 182, 537.

34. Moldave, K., and Meister, A. Synthesis of phenylacetylglutamine by human tissue. J. biol. Chem. 1957, 229, 463.

35. Sherwin, C. P., and Kennard, K. S. Toxicity of phenylacetic acid. J. biol. Chem. 1919, 40, 259.

36. Ladd, J. N., and Nossal, P. M. The chromatographic separation and identification of organic acids and their application to yeast. Aust. J. exp. Biol. med. Sci. 1954, 32, 523.

37. Harrison, T. R., and Mason, M. F. The pathogenesis of the uremic syndrome. Medicine (Baltimore) 1937, 16, 1.

38. Olsen, N. S., and Bassett, J. W. Blood levels of urea nitrogen, phenol, guanidine and creatinine in uremia. Amer. J. Med. 1951, 10, 52.

39. Christensen, H. N., Decker, D. G., Lynch, E. L., Mackenzie, T. M., and Powers, J. H. The conjugated, non-protein, amino acids of plasma. V. A study of the clinical significance of peptidemia. J. clin. Invest. 1947, 26, 853. 